\title{
A Comparative Study of Chinese and English Quantifiers
}

\author{
Wei Shen ${ }^{1 *}$ \\ ${ }^{1}$ School of Foreign Languages, Northeast Electric Power University, Jilin, Jilin 132012 China \\ *Corresponding author. Email: neduce@sina.com
}

\begin{abstract}
There is a word group called "quantifiers" in Chinese, whereas, but there is no such phrase in English. Chinese quantifiers have now become an important part of Chinese vocabulary. This paper aimed to make a brief comparison between English and Chinese quantifiers in terms of structure, classification, grammatical features and ideographic functions. The meaning of Chinese quantifier expression is relatively wide, and the meaning of English quantifiers is narrower. There are more Chinese single quantifiers in special specificity, and the number of group quantifiers is few but it is more versatile in Chinese, oppositely; in English, the group quantifiers are more and with strong specificity, and the number of single quantifiers is small and general. Chinese quantifiers must be used in conjunction with numerals, without plural form, in English, most nouns can usually be used with numerals or indefinite articles directly, and with a single or plural form. Chinese quantifiers are more general, while English quantifiers are more concrete.
\end{abstract}

Keywords: Comparison, Chinese, English, quantifier

\section{INTRODUCTION}

The concept of quantity, which is closely related to numbers, naturally has a long historical origin in China. From ancient Yin Shang period, degrees, quantities, scales, containers and currency unit words were used. In the later Han and Wei Six dynasties, Yuan Ming period, quantifiers had some new developments, its system and usage has become closer to the quantifiers of modern Chinese.

As a branch of Sino-Tibetan language family, Chinese has an extremely rich group of quantifiers, which is a very active and useful word category, and most of them come from nouns. English, which belongs to the Indo-European family, does not have the independent lexical category of quantifiers in traditional grammatical system, but the concept of the amount of expression has always existed. Some linguists refer to these nouns as special quantifiers, while others, represented by Quirk et al. [1], classified quantifiers under the noun category and referred to them as quantitative and partitive nouns, most English grammar books do not specifically include English quantifiers. But their existence as "quantifiers" is objectively a fact, because the noun of units or a noun with a quantitative meaning actually refers to a quantifier [2].

Quantifiers, nouns, verbs, adjectives have the same grammatical status, they can be used as content words in a sentence, so the widespread use of quantifiers has become the characteristics of modern Chinese. But in the vocabulary system of English, quantifiers are underdeveloped. There is no "quantifiers" in the ten lexical categories of English, and the words that denote the units of people or things and a small number of action units are listed under nouns. The quantifiers in English have not become an independent word category like Chinese quantifiers, that is, not like verbs, nouns, adjectives that belong to the content words, nor like prepositions, articles which belong to function words.

\section{STRUCTURE OF QUANTIFIERS}

The structure of Chinese quantifiers is often in "numeral + quantifier + noun"; the quantifier structure of English is "numeral + quantifier + of + noun". For example, "四条狗" in Chinese, the "条" is a quantifier, which means the number unit of "dog", "四" is a numeral, which indicates the quantity of "条", and shows "numeral + quantifier + noun" the quantifier structure. Similarly, in English, "bottle" in "six bottles of milk" is the number unit that represents "the unit f milk", while "six" is the numeral, which means the number of "bottle", so the structure is "numeral + quantifier + of + noun ".

As Quirk et al. [3] points out, English often uses nouns and prepositions to complete the task of quantity, the expression of which is "A/number $+\mathrm{N} 1+$ of $+\mathrm{N} 2$ ", that is, the quantifier structure of "numeral + quantifier + of + noun" as we call it here.

\subsection{Classification of quantifiers}

Chinese quantifiers are used between numerals and nouns, to denote the units of things. Despite it has long history, there have been controversies about its classification, and there are two influential ones.

The first is to divide Chinese quantifiers into two categories: the quantifier of person or object is called content quantifier: the quantifier of action or behavior is called dynamic quantifier [4].

(1) Content quantifiers 
(1) weights and measures of the unit.

Such as: "chi, cun, dun" and so on.

(2) general quantifiers

Such as: "ge, zhi, ben, jian" and so on.

(3) a quantifier measured by the characteristics and state of a thing

Such as: "tou, kou, fa, tiao" and so on.

(2) Dynamic quantifiers

(1) special dynamic quantifiers

Such as: ci, bian, fan, zhen, dun" and so on.

(2) borrowed dynamic quantifiers

Generally, it is borrowed from nouns related to action.

Such as: "dao (cut), bi (write), shua (brush)" and so on.

According to Zhang and $\mathrm{Lu}$ [5], another classification of Chinese quantifiers is by the combination of its structure and function, which divides it into three levels: the first level is simple quantifiers and compound quantifier; the second level is the internal classification of simple quantifiers, with single quantifiers, group quantifiers, partial quantifiers, metric quantifiers, category quantifiers and dynamic quantifiers; and the third level is the internal classification of group quantifiers and metric quantifiers, it consists of quantitative group quantifiers, non-quantitative group quantifiers, legal metric quantifiers and customary metric quantifiers.

Although this classification has some cross-category problems, on the whole, the logical relationship between levels is clearer and more scientific, look at the following examples:

(1) Simple quantifiers

(1) single quantifiers

Such as: "ge, lv, zhi, zhang, kou" and so on.

(2) group quantifiers

Quantitative group quantifiers

Such as: "bu, da, shuang, hu, ji" and so on.

Non-quantitative group quantifiers

Such as: "ba, pi, fen, chuan, bao" and so on.

(3) partial quantifier

Such as: "ceng, kuai, pian, duo, bi" and so on.

(4) metric quantifier

Legal metric quantifiers

Such as: "chi, mi, miao, qing, gongli" and so on.

Customary metric quantifiers

Such as: "bei, bu, bei, pi, zhan" and so on.

(5)Category quantifiers

Such as: "ge, lei, yang, zhong" and so on.

(6)Dynamic quantifiers

Such as: "ci, hui, dun, chang" and so on.

(7)compound quantifier

Such as: "banci, huitai, qianwa xiaoshi, dun gongli" and so on

Strictly speaking, there is no correspondence of quantifiers from Chinese to English. Some linguists refer to the noun concept as a "special quantifier", while Quirk et al. (1972), in "A Grammar of contemporary English", refers to them as "partitive nouns", while in his other grammar book "A comprehensive Grammar of the English Language" is called "partitive construction" because these quantifiers could not perform the task of expressing measure or quantity without the help of nouns and prepositional structures, in the form of a+ N1+ of $+\mathrm{N} 2$.

However, such quantifier structure still belongs to nouns. It can also be further divided into three categories: type structure, quantity structure and unit of measure nouns. In the structure of a+ N1+ of $+\mathrm{N} 2, \mathrm{~A}$ is an article, $\mathrm{N} 1$ is a countable noun as measure, most of which are borrowed from common nouns, with plural forms, N2 as measured objects, including countable nouns and uncountable nouns. Quirk et al. [3] classify measure partitive nouns as the third one, because they are the units of accurate measurement. In other words, the measure partitives relate to precise quantities denoting length, area, volume and weight.

For example:

a mile of cable /a hectare of land/a quart of milk /a kilo of apples/two gallons of water/two kilos of apples

In this quantitative structure, of which $\mathrm{N} 1$ is a proprietary unit of measure, a countable noun with single or plural form; N2 is a measured object, including countable and uncountable nouns, with single or plural form.

Chinese metric quantifiers and English measure partitive nouns have some similarities, such as "chi, mi, miao, gongli", their English correspondences, "inch, meter, second, kilometre". In addition, the dynamic quantifiers of Chinese generally have proprietary special words (ci, hui, bian, dun, etc.) and borrowed words (da yi dun, kan yi yan, e yi tian, etc.); English also has the corresponding "twice, three times" with Chinese and the form of verb nominalization and cognate object, such as: "have a bite, dream a dream, smile a smile", etc.

\subsection{Single quantifiers and group quantifiers}

The differences in Chinese and English quantifiers are also obvious in single quantifiers and group quantifiers. There are two characteristics of single quantifiers in Chinese. One is that it has a big quantity and the other is with strong specificity. When individual nouns in Chinese should be connected with single quantifiers, such as: "一位女士, 一 戞灯, 两栋房子" and so on.

English individual noun is also a very large and open word category; it can be used directly with numerals or indefinite articles without the need for quantifiers. such as: "two books", "six cars", "seven lathes" and so on. Under certain conditions, due to the need of quantity, the individual quantitative structure of English appears to be fewer, but more versatile than that of the Chinese, commonly used quantifiers are "piece, sheet, drop. speck" and so on, of which "piece" is the most active word, covering the widest range.

The following is the comparison between English and corresponding Chinese single quantifiers in the example of "piece":

a piece of wood 一块木头/a piece of furniture 一件衣服/a piece of information一条消息/a piece of poetry 一首诗/a piece of music 一支乐曲/a piece of prose 一篇散文/a 
piece of good luck 一个好运气/a piece of kindness 一番 好意/a piece of folly thing 一桩蚌事

The group quantifiers in Chinese are fewer and more versatile than English. For instance, "ban, dui, qun, pi, ba, dui, gu, xie, dian'er" and so on. On the contrary, the structure of English group quantifiers is more and in specificity, which is a huge system. Expressing pairs, there are "a pair of, a couple of, a brace of, a span of, a yoke of" and so on; For a small number: "a corps of, a band the of, a clump of, a party of "; For a large number, such as, "a cloud of, a hatch of, a galaxy of, a swarm of, an ocean of "; Indicating a series of, such as, "a series of, a stream of, a file of, a line of"; Expressing dynamic: "a flow of, a stampede of, a gaggle of, a drove of "; As a derogatory expression, " a hunch of, a gang of, a mob of, a band of ". In addition, the structure of animal group quantifiers expressed in English is more complex and more specialized. There are for groups of insects, such as, "a hive of, a cloud of, an army of", and the list of aquatic fauna, such as, "a bale of, a school of, a pod of ". There are groups of birds, "a bevy of, a cam of, a host of, a wisp of". For a tribe of animals, they are, "a kennel of, a collection of". A herd of animals, such as "a brood of, a farrow of". Some are from verbs or the use of geographical nouns to denote animal groups, such as: "a fall of, a desert of, a flight of, a walk of, a field of". Furthermore, English also has a large number of expressions of emotional, climatic and other aspects of the quantifier structure.

Besides the above, the quantifier structure of English has the tendency to disintegrate in spoken language, and instead, the numerals are directly combined with $\mathrm{N} 2$ in the quantifier structure. For example: "A beer (glass of beer), a coke (a glass of coke, or a can of coke), two butters and six sugars (A/packets of butter and six lumps of sugar).

\section{GRAMMATICAL FEATURES AND FUNCTIONS OF QUANTIFIERS}

\subsection{Grammatical features}

\subsubsection{Combination with words}

Modern Chinese quantitative word system is a special subsystem in the contemporary lexical system. The stereotyped combination of numerals and quantifiers, which regulate each other, determines the basic function of quantifiers--number is connected with quantifiers, and also the identification criteria that quantifiers are decided by numerals, under general circumstances (Xing, 1995).

Although most of the quantifier structures in English are connected with numerals, but there are some exceptions, some of which are in the N1 position before the noun can not combine with numerals. Such as: "a quantity of, an amount of ".

\subsubsection{Single and plural form}

In Chinese, there is not single or plural form for quantifiers, for example: “一条毛巾, 三件衣服”, whereas, in English, the noun in N1 position has a single or plural form, such as:" a bar of soap, two drops of the river ".

\subsubsection{Overlapping use}

Most of the quantifiers in Chinese are monosyllable, which can be overlapped in usage. Overlapping quantifiers have different functions and positions in sentence, which can be used as attributive, adverbial and predicate and so on.

For example:

条条大路通罗马 (条条-attributive)

件件是出于好意 (件件--subject)

天空白云片片, 地上牛羊点点 (片片, 点点-predicate)

秋风阵阵吹来, 好不凉爽 (阵阵-adverbial)

In addition, the monosyllable quantifiers also have three overlapping forms:

(1) numeral (one) AA: 一步步, 一行行

(2) numeral A + number A: 一个一个, 一跳一跳

(3) numeral $\mathrm{AB}+$ Number $\mathrm{AB}$ : 一平方米一平方米, 一整 块一整块

However, there is no overlapping form in English quantifier structure.

In modern Chinese, quantifiers generally do not act as an element of a sentence alone (except for overlapping forms of quantifiers), nor do they answer questions alone. Quantifiers often form a number of phrases together with numerals, acting as sentence components or answering questions.

For example,

一对一对的士兵走过去了

In the sentence, "一对一对" is an attributive.

Q: “要多少?”

A: "二杯"

The "二杯" answers the question directly. The numeral“二

" is used together with quantifier" 杯" to answer a question.

In English, quantifiers together with numeral and nouns, constitute a noun phrase to act as an element in a sentence.

For example:

He gave me a piece of advice. (object)

A bar of chocolate was wanted. (subject)

English quantifiers are generally borrowed from common nouns, so it has lexical meaning. They also have the function of nouns. It can be used alone, in the sentence as the subject, object and so on.

For example:

A bottle is what he needs. (Subject)

Give me a bottle, please. (Object) 


\subsection{Ideographic function of quantifiers}

Generally speaking, the meaning of Chinese quantifiers is relatively broad, more general, and English quantifiers represent a narrower meaning, more specific, often can express subtle meaning differences in same category.

Sometimes, one Chinese quantifier that appears in different combinations often has to be expressed in several, more than 10 or even dozens of different English quantifiers.

Take the Chinese quantifier "群" as an example, which means "people or things gathered together", can be paired with it, regardless of the object and its state.

For example,

一群学生 (refers to people)/一群燕子 (refers to birds)/一 群鱼 (refers to aquatic animals)/一群羊 (refers to cattle)

In English, in the sense of the Chinese quantifier "群" corresponding to English words: "crowd, group, host, troop, galaxy, band, gang, mob, horde, pack, clump, shoal, body, flock, herd" and so on.

In addition to the common meaning of "people or things that gather together", they also contain additional subtle differences in meaning. Chinese quantifiers "套 ", in English it could be: "set, series, gang, suit, suite, nest" and so on. Chinese quantifiers "层", corresponding English are: "layer, veil, coating, film, thickness, bed, flake, cloak, tier" and so on.

The phenomenon that several English quantifiers correspond to a Chinese quantifier is not rare. The collocation of English quantifiers and nouns is generally fixed, and its ideographic function is narrower. Of course, there are several Chinese quantifiers that correspond to one English quantifier, such as English quantifier "piece" in Chinese quantifiers are "pian, kuai, duan, zhang, fan, ge, fu, jian, juan" and so on, as follows:

a piece of bread 一块面包/a piece of paper 一张纸/a piece of wood 一段木材 /a piece of furniture 一件家具/a piece of advice一个忠告/a piece of land 一块地 / a piece of wall paper (一卷糊墙纸)

The English quantifier "pair" corresponds to the Chinese quantifiers "fu, tao, tiao, dui" and so on. This phenomenon that one English quantifier corresponds to several Chinese quantifiers is much less than the situation that a Chinese quantifier corresponds to several English quantifiers. There is also a Chinese quantifier which only corresponds to one English quantifier, this situation mainly appears in the quantifiers that express weights and measures, containers and dynamic quantifiers.

For example:

a yard of cloth 一码布/a ton of coal一吨煤/a pound of butter一磅黄油/a cup of tea一杯茶

\section{CONCLUSION}

Summarizing the above comparisons, it can be seen that Chinese and English quantifiers have obvious similarities and differences. The main differences are manifested in structure, classification, grammatical and ideographic function. There is a word group in Chinese named as "quantifier", but in English there is only quantifier structure, and no independent lexical category for it. In Chinese, the single quantifiers are more in quantity and the specificity is strong, the group quantifiers are fewer and more versatile. In English, on the contrary, the group quantifiers are more and with strong specificity, and the number of single quantifiers is small and general. In grammatical function, Chinese quantifiers must be used in conjunction with numerals, without plural form, while in English, most nouns can usually be used with numerals or indefinite articles directly, and with a single or plural form. When the structure a $+\mathrm{N} 1+$ of $+\mathrm{N} 2$ is used, nouns in $\mathrm{N} 1$ position also have a single or plural form, sometimes without numerals. N1 acts more like a noun, there could be a variety of modifiers before N1. Chinese single quantifiers can be overlapped, but English quantifiers cannot. From the view of ideographic function, Chinese quantifiers are more general, English quantifiers are more concrete and detailed.

\section{REFERENCES}

[1] R. Quirk, S. Greenbaum, G. Leech, J. Svartvik. A Grammar of the Contemporary English, Longman Group Ltd., 1972.

[2] K. Allan, Classifiers, Language (2) (1977) 285-311.

[3] R. Quirk, S. Greenbaum, G. Leech, J. Svartvik. A Comprehensive Grammar of the English Language, Longman Group Ltd, 1985

[4] D. X. Zhu. Grammar handbook, The Commercial Press, 1982.

[5] D. F. Zhang, W. Z. Lu, Cognitive rationale of nomenclature: A comparative study of English and Chinese based on similarity, Journal of Xi'an Foreign Studies University 21(2) (2013) 7-10. DOI: CNKI:SUN:XAWX.0.2013-02-003 